\title{
Frequency of Thyroid-Stimulating Hormone Monitoring in Patients After Thyroidectomy: A Retrospective Study in Primary Care Practices in Germany
}

\author{
Authors \\ Karel Kostev ${ }^{\text {, Margarethe Winiarski² }}{ }^{2}$ Lisa Schüller², Andreas M. Sesterhenn², Louis Jacob ${ }^{3}$
}

\begin{abstract}
Affiliations
1 Epidemiology, IQVIA, Frankfurt, Germany

2 Department of Otorhinolaryngology, Head and Neck Surgery, Solingen Municipal Hospital, Solingen, Germany

3 Faculty of Medicine, University of Paris 5, Paris, France
\end{abstract}

\section{Key words}

thyroid-stimulating hormone, monitoring, thyroidectomy, primary care

$\begin{array}{ll}\text { received } & 13.12 .2017 \\ \text { revised } & 26.12 .2017 \\ \text { accepted } & 02.01 .2018\end{array}$

Bibliography

DOI https://doi.org/10.1055/s-0044-100038

Published online: 2.2.2018

Exp Clin Endocrinol Diabetes 2018; 126: 640-644

(c) J. A. Barth Verlag in Georg Thieme Verlag KG Stuttgart . New York

ISSN 0947-7349

\section{Correspondence}

Prof. Dr. rer. med. Karel Kostev

Epidemiology IQVIA Darmstädter

Landstraße 10860598 Frankfurt am Main

Germany

Tel.: + 49/69/66 044878

kkostev@de.imshealth.com

\section{ABSTRACT}

Aim The goal of this study was to analyze the frequency of thyroid-stimulating hormone (TSH) monitoring in thyroidectomy patients followed by general practitioners in Germany.
Methods This study included all individuals $\geq 18$ years who had undergone a thyroidectomy between 2000 and 2015 in 258 general practices in Germany. Another inclusion criterion was a minimum of three medical visits between 2015 and 2016, following thyroidectomy. The primary outcome was the annual frequency of TSH monitoring in thyroidectomy patients in 2015. Demographic data included age, sex, and type of health insurance coverage (private versus statutory). Clinical and therapeutic data included the amount of time since the first thyroidectomy, thyroidectomy-associated diagnosis (thyroid cancer, noncancerous enlargement of the thyroid (goiter), or hyperthyroidism), type of thyroidectomy (total or hemithyroidectomy), the Charlson Comorbidity Index score, and the prescription of levothyroxine therapy in 2015. A multivariable logistic regression model was performed to identify variables potentially associated with the likelihood of having been tested at least once for TSH in the year 2015.

Results The present study included 1,135 thyroidectomy patients. The mean age was 60.1 years $(S D=14.3$ years), and $75.8 \%$ of the patients were women. TSH was measured at least once in $42.3 \%$ of patients. In addition, $31.5 \%$ of individuals after thyroidectomy had mean TSH values between 0.25 and $1 \mathrm{mIU} / \mathrm{L}$ in 2015. No variable was significantly associated with the frequency of TSH monitoring. However, there was a tendency toward a lower TSH monitoring frequency in the groups which had undergone thyroidectomy years ago $(\mathrm{OR}=0.77$ (95\% Cl: $0.53-1.11)$ for $1-5$ years and $\mathrm{OR}=0.67(95 \% \mathrm{Cl}$ : $0.45-0.99$ ) for $>5$ years compared to $<=1$ year).

Conclusions Only $40 \%$ of thyroidectomy patients followed by general practitioners in Germany were monitored at least once for TSH in 2015.

\section{Introduction}

Thyroidectomy is a common surgery performed in approximately 60,000 patients in Germany each year [1]. The most frequent indications for thyroidectomy are cancer or suspected cancer [2], hyperthyroidism [3], and goiters of considerable size [4]. Thyroidectomy can be either partial or total, and previous research has compared the different surgical outcomes [5]. Thyroidectomy is considered safe and is associated with an increase in the quality of life $[1,6]$.

There exists a risk of hypothyroidism in the weeks and months following surgery, depending on the type of thyroidectomy. It is estimated that around $30 \%$ of hemithyroidectomy patients will develop hypothyroidism $[7,8]$. Risk factors for this complication notably include a pathological diagnosis (Hashimoto thyroiditis and 
multinodular goiter) and high initial serum thyrotropin levels [7]. It is further known that all patients with total thyroidectomy will be affected by hypothyroidism [9]. Thus, optimal levothyroxine replacement therapy is crucial after thyroidectomy. It is recommended that thyroid-stimulating hormone (TSH) levels be measured four to six weeks after each change in the hormone dose or in the clinical presentation [9], and once per year after the optimal levothyroxine therapy has been identified [10]. In 2006, Verhaert and colleagues showed based on TSH measurements that levothyroxine replacement therapy was not satisfactory in the majority of individuals after thyroidectomy and required further adjustments [11]. Other authors have also highlighted the fact that physicians often experience difficulties in finding the appropriate L-thyroxin replacement therapy and the appropriate therapeutic TSH ranges following thyroidectomy [9].

Although these findings are of particular importance, little is known about the exact frequency of TSH monitoring after thyroidectomy in primary care practices. Therefore, the goal of the present study was to analyze the frequency of TSH monitoring in thyroidectomy patients followed by general practitioners in Germany.

\section{Methods}

\section{Database}

The present retrospective analysis was based on the nationwide Disease Analyzer database (QuintilesIMS). This database includes demographic, clinical and pharmaceutical variables, which are longitudinally and anonymously obtained from a nationwide sample of general and specialist practices [12]. The quality and exactness of these data are regularly assessed by QuintilesIMS, and it has been previously determined that the Disease Analyzer database is representative of German practices [12].

\section{Study population and inclusion criteria}

Thyroidectomy diagnosis was defined using the documentation provided by physicians. This study included all individuals $\geq 18$ years who had an initial documentation of "a condition after thyroidectomy" between January 2000 and December 2014 in 258 general practices in Germany. To ensure continuous follow-up, patients were only included if they had at least two physician visits in 2015 and one visit in 2016 ( $\triangleright$ Fig. 1).

\section{Study outcome and independent variables}

The primary outcome was the annual frequency of TSH monitoring in thyroidectomy patients in 2015. Demographic data included age, sex, and type of health insurance coverage (private versus statutory). Clinical and therapeutic data included the time between first thyroidectomy documentation and first TSH monitoring, thyroidectomy-associated diagnosis (thyroid cancer [C73], noncancerous enlargement of the thyroid (goiter) [E04, D34], hyperthyroidism [E05]), type of thyroidectomy (total or hemithyroidectomy), the Charlson Comorbidity Index score, and the prescription of levothyroxine therapy in 2015.

\section{Statistical analyses}

Descriptive analyses were obtained for all demographic variables and mean \pm SDs were calculated for continuous variables. A multivariable logistic regression model was performed to identify variables associated with the likelihood of having been tested at least once for TSH in the year 2015. This threshold was selected based on the recommendation to measure TSH once per year during the long-term follow-up of thyroidectomy patients. A logistic regression model was performed to analyze the impact of demographic, clinical, and therapeutic variables on the odds of TSH monitoring. A p-value $<0.05$ was considered statistically significant. All analyses were carried out using SAS 9.3 (SAS Institute, Cary, NC, USA).

\section{Results}

The present study included 1,135 thyroidectomy patients ( $\bullet$ Table 1 ). The mean age was 60.1 years ( $S D=14.3$ years), and $75.8 \%$ of the patients were women. The mean time between first thyroidectomy documentation and first TSH monitoring was 4.7 years $(S D=3.3$ years), and $93.1 \%$ of patients were prescribed levothyroxine. The mean number of TSH measurements in 2015 is displayed in > Fig. 2. TSH was measured at least once in $42.3 \%$ of patients. In addition, $81.0 \%$ of individuals after thyroidectomy had mean TSH values between 0.25 and $4 \mathrm{mIU} / \mathrm{L}$ in 2015 ( $>$ Fig. 3). $>$ Table 2 shows the results of the logistic regression model. No variable was significantly associated with the frequency of TSH monitoring.

However, there was a tendency toward a lower TSH monitoring frequency in the groups which had undergone thyroidectomy years ago $(\mathrm{OR}=0.77(95 \% \mathrm{Cl}: 0.53-1.11)$ for $1-5$ years and $\mathrm{OR}=0.67$ (95\% Cl: $0.45-0.99)$ for $>5$ years compared to $<=1$ year).

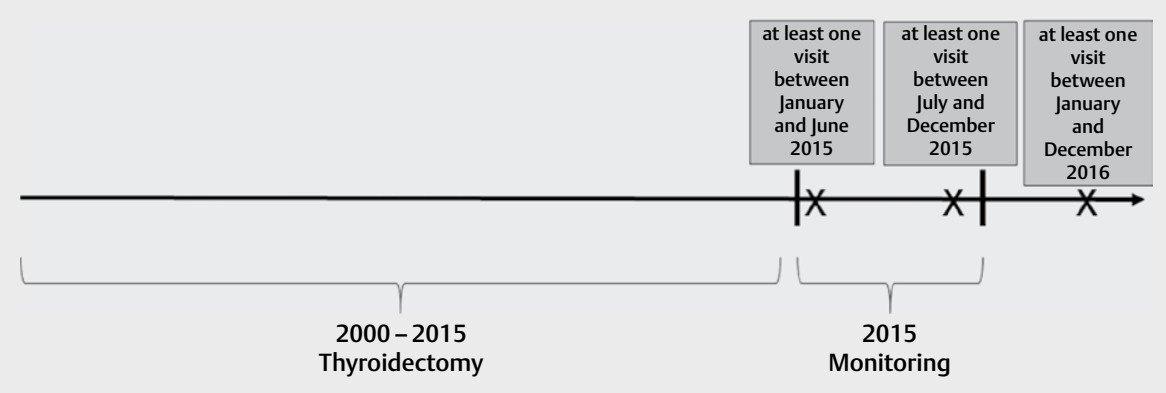

Fig. 1 Study design. 
- Table 1 Baseline characteristics of the study population (Disease Analyzer Database, IQVIA).

\begin{tabular}{|c|c|}
\hline Variable & Value \\
\hline $\mathrm{N}$ & 1,135 \\
\hline \multicolumn{2}{|l|}{ Demographic variables } \\
\hline Age (Mean, SD) & $60.1(14.3)$ \\
\hline$\leq 50$ years $(\mathrm{N}, \%)$ & $306(27.0)$ \\
\hline $51-60$ years $(N, \%)$ & 271 (23.9) \\
\hline $61-70$ years $(N, \%)$ & 245 (21.6) \\
\hline$>70$ years $(\mathrm{N}, \%)$ & $313(27.6)$ \\
\hline Women (N, \%) & $860(75.8)$ \\
\hline Private health insurance coverage $(\mathrm{N}, \%)$ & $161(14.2)$ \\
\hline \multicolumn{2}{|l|}{ Time (in years) since first thyroidectomy } \\
\hline Mean (SD) & $4.7(3.3)$ \\
\hline$\leq 1$ year $(\mathrm{N}, \%)$ & $164(14.5)$ \\
\hline$>1-\leq 5$ years $(\mathrm{N}, \%)$ & $593(52.3)$ \\
\hline$>5$ years $(\mathrm{N}, \%)$ & $378(33.3)$ \\
\hline \multicolumn{2}{|c|}{ Diagnoses associated with thyroidectomy prior to 2015} \\
\hline Thyroid cancer (ICD 10: C73) (N, \%) & $240(21.5)$ \\
\hline $\begin{array}{l}\text { Noncancerous enlargement of the thyroid } \\
\text { (goiter) (ICD 10: E04, D34) (N, \%) }\end{array}$ & $550(48.5)$ \\
\hline Hyperthyroidism (ICD 10: E05) (N, \%) & $260(19.0)$ \\
\hline \multicolumn{2}{|l|}{ Type of thyroidectomy } \\
\hline Total thyroidectomy (N, \%) & $876(77.2)$ \\
\hline Hemithyroidectomy (N, \%) & $229(22.8)$ \\
\hline \multicolumn{2}{|l|}{ Co-morbidity } \\
\hline Charlson Comorbidity Index (SD) & $1.7(1.5)$ \\
\hline Index 1 (N, \%) & $849(74.8)$ \\
\hline Index 2-3 (N, \%) & $230(2.3)$ \\
\hline Index >3 (N, \%) & $56(4.9)$ \\
\hline \multicolumn{2}{|l|}{ Therapy with levothyroxine in 2015} \\
\hline Yes (N, \%) & $1,057(93.1)$ \\
\hline No (N, \%) & $78(6.9)$ \\
\hline
\end{tabular}

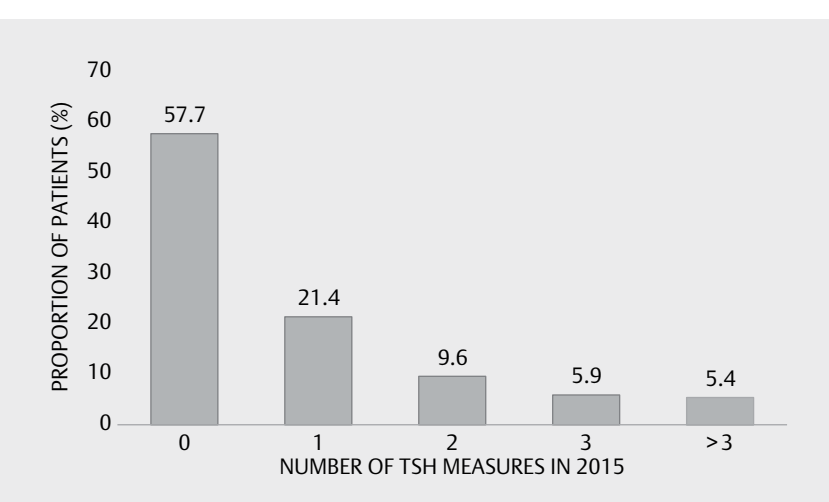

- Fig. 2 Number of TSH measurements per patient in 2015.

\section{Discussion}

The present retrospective study, which included more than 1,100 thyroidectomy patients followed in general practices in Germany, showed that approximately $42 \%$ of the population received at least one TSH measurement in 2015. It was further discovered that the

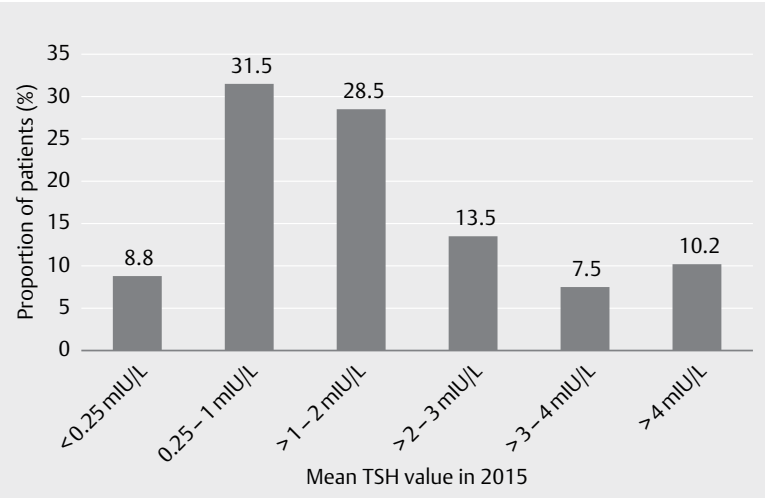

Fig. 3 Mean TSH value in thyroidectomy patients followed by general practitioners in Germany.

majority of individuals displayed TSH levels between 0.25 and $4 \mathrm{mIU} / \mathrm{L}$. Finally, no variable was significantly associated with the likelihood of having been prescribed at least one TSH measurement in 2015. However, there was a negative trend between the time since thyroidectomy and the frequency of TSH monitoring.

Only few studies have focused on levothyroxine replacement therapy after thyroid surgery in recent years [13-15]. A 2006 study conducted in Belgium, which included 87 patients undergoing thyroidectomy for benign thyroid pathology, investigated the adequacy of thyroid hormone replacement therapy three months after total, subtotal, or hemithyroidectomy [11]. Within the subgroup of patients with adequate TSH levels prior to the surgery, the authors showed that an adjustment in levothyroxine replacement therapy was required in $45 \%$ of those with total thyroidectomy, $42 \%$ of those with subtotal thyroidectomy, and $17 \%$ of those with hemithyroidectomy. In the subgroup of people with preoperative hyperthyroidism, they found that $60 \%$ of those with total thyroidectomy and all patients with subtotal thyroidectomy required hormone dose adjustments. These findings clearly suggest that it is difficult to arrive at an optimal replacement therapy after thyroidectomy and that subsequent adjustments are required in most cases. More recently, Scargill et al. further investigated the frequency of thyroid function monitoring in patients on levothyroxine in the UK [16]. They showed that the majority of tests were performed outside recommended intervals and that there was high variability between practices. Although this research did not focus on people who had undergone thyroidectomy, it underlines the fact that there is need for improvement when it comes to monitoring thyroid function in individuals receiving levothyroxine.

The important finding of this study is that nearly $60 \%$ of the population was not monitored for TSH in 2015. This result is cause for concern since at least one TSH measurement is recommended per year $[9,10]$. One major hypothesis that could explain this finding is that most patients were satisfied with their levothyroxine therapy and did not exhibit symptoms of hyperthyroidism (i. e. tachycardia, weight loss, or nervousness) or hypothyroidism (i. e. fatigue, constipation, or muscle weakness). In line with this hypothesis, a high proportion of the population displayed TSH levels between 0.5 and $4 \mathrm{mIU} / \mathrm{L}$. Although our work was unable to identify risk factors potentially associated with the likelihood of having received at 
- Table 2 Association between demographic, clinical, and therapeutic data and the frequency of TSH measurements in thyroidectomy patients in 2015 (logistic regression models).

\begin{tabular}{|c|c|c|c|}
\hline Variables & $\begin{array}{l}\text { Patients with at } \\
\text { least one TSH } \\
\text { measurement } \\
\text { in } 2015(\%)\end{array}$ & OR $(95 \% \mathrm{Cl})$ & $\begin{array}{c}\text { p- } \\
\text { value }\end{array}$ \\
\hline \multicolumn{4}{|c|}{ Demographic variables } \\
\hline$\leq 50$ years & 42.8 & Reference & \\
\hline $51-60$ years & 34.3 & $0.75(0.52-1.08)$ & 0.121 \\
\hline $61-70$ years & 44.1 & $1.08(0.74-1.56)$ & 0.697 \\
\hline$>70$ years & 47.3 & $1.25(0.88-1.78)$ & 0.209 \\
\hline Men & 38.2 & Reference & \\
\hline Women & 43.6 & $1.25(0.93-1.70)$ & 0.145 \\
\hline $\begin{array}{l}\text { Private health } \\
\text { insurance coverage }\end{array}$ & 35.4 & $0.75(0.51-1.12)$ & 0.161 \\
\hline $\begin{array}{l}\text { Statutory health } \\
\text { insurance coverage }\end{array}$ & 43.4 & Reference & \\
\hline \multicolumn{4}{|c|}{ Time since first thyroidectomy in years } \\
\hline$\leq 1$ year & 47.0 & Reference & \\
\hline$>1-\leq 5$ years & 42.7 & $0.77(0.53-1.11)$ & 0.236 \\
\hline$>5$ years & 39.7 & $0.67(0.45-0.99)$ & 0.089 \\
\hline \multicolumn{4}{|c|}{ Diagnoses associated with thyroidectomy prior to 2015} \\
\hline Thyroid cancer & 43.8 & $1.05(0.64-1.73)$ & 0.839 \\
\hline Hyperthyroidism & 49.5 & $1.36(0.98-1.89)$ & 0.062 \\
\hline $\begin{array}{l}\text { Noncancerous } \\
\text { enlargement of the } \\
\text { thyroid }\end{array}$ & 41.1 & Reference & \\
\hline \multicolumn{4}{|c|}{ Type of thyroidectomy } \\
\hline Hemithyroidectomy & 39.0 & $0.95(0.71-1.28)$ & 0.662 \\
\hline Total thyroidectomy & 43.3 & Reference & \\
\hline \multicolumn{4}{|l|}{ Co-morbidity } \\
\hline Index 1 & 41.6 & Reference & \\
\hline Index 2-3 & 43.5 & $1.09(0.68-1.76)$ & 0.952 \\
\hline Index $>3$ & 48.2 & $1.23(0.61-2.47)$ & 0.784 \\
\hline $\begin{array}{l}\text { Therapy with } \\
\text { levothyroxin in } 2015\end{array}$ & 42.4 & $1.22(0.75-1.97)$ & 0.764 \\
\hline $\begin{array}{l}\text { No therapy with } \\
\text { levothyroxin in } 2015\end{array}$ & 41.0 & Reference & \\
\hline
\end{tabular}

least one TSH measurement in 2015, it is possible that some demographic and/or clinical variables play a major role in this prescription pattern, thus underlining the importance of new studies aimed at identifying these factors. Of particular interest was the negative trend we discovered between the time since thyroidectomy and the chance of having received $\geq 1 \mathrm{TSH}$ measurement. This finding might be explained by the fact that the adjustment of levothyroxine doses is made during the first months of the therapy. Therefore, it is likely that the number of TSH measurements decreases over time, and that people who have undergone recent thyroidectomy are more often monitored for TSH than those who have undergone thyroidectomy years ago. On the other side, the monitoring of TSH is very important in older people as with an increase in age, changes in thyroid hormone production can occur.

This study was subject to several limitations that should be mentioned at this point. First, TSH values were only available in a share of general practices, thus potentially introducing a bias to the subsequent statistical analyses. Second, we were unable to include endocrinological practices, although a notable proportion of patients with thyroidectomy might be followed in these practices. Third, there was no data on the socioeconomic status of patients, even though the frequency of TSH monitoring might be impacted by this status. The two major strengths of this work were the large number of individuals available for analysis and the fact that we used a nationwide real-world database, allowing for unbiased estimation of the monitoring frequency of TSH in primary care practices in Germany.

Overall, only $40 \%$ of thyroidectomy patients followed by general practitioners in Germany were monitored at least once for TSH in 2015. Further research is needed to gain a better understanding of the demographic and clinical factors which have a potential impact on the likelihood of being prescribed TSH monitoring in general practices.

\section{Acknowledgments}

Professional English language editing services were provided by Claudia Jones, MA, Radford, Virginia, United States.

\section{Funding}

The authors have received no financial support for the research, authorship, and/or publication of this article.

\section{Conflict of Interest}

No conflict of interest has been declared by the authors.

\section{References}

[1] Fortuny JV, Guigard S, Karenovics W et al. Surgery of the thyroid: Recent developments and perspective. Swiss Med Wkly 2015; 145: w14144

[2] Callender GG, Carling T, Christison-Lagay E et al. Surgery for thyroid cancer. Endocrinol Metab Clin North Am 2014; 43: 443-458

[3] Quérat C, Germain N, Dumollard J-M et al. Surgical management of hyperthyroidism. Eur Ann Otorhinolaryngol Head Neck Dis 2015; 132: 63-66

[4] Geerdsen JP, Frølund L. Thyroid function after surgical treatment of nontoxic goitre. A randomized study of postoperative thyroxine administration. Acta Med Scand 1986; 220: 341-345

[5] Corso C, Gomez X, Sanabria A et al. Total thyroidectomy versus hemithyroidectomy for patients with follicular neoplasm. A cost-utility analysis. Int J Surg Lond Engl 2014; 12: 837-842

[6] Sorensen JR, Watt T, Cramon P et al. Quality of life after thyroidectomy in patients with nontoxic nodular goiter: A prospective cohort study. Head Neck 2017; 39: 2232-2240

[7] Miller FR, Paulson D, Prihoda T] et al. Risk Factors for the Development of Hypothyroidism After Hemithyroidectomy. Arch Otolaryngol Neck Surg 2006; 132: 36-38 
[8] Chotigavanich C, Sureepong P, Ongard S et al. Hypothyroidism after Hemithyroidectomy: The Incidence and Risk Factors. J Med Assoc Thail Chotmaihet Thangphaet 2016; 99: 77-83

[9] Schäffler A. Hormone Replacement After Thyroid and Parathyroid Surgery. Dtsch Ärztebl Int 2010; 107: 827-834

[10] NHS Foundation Trust. Guidelines for thyroid function testing [Internet]. 2014; [no volume].

[11] Verhaert N, Vander Poorten V, Delaere P et al. Levothyroxine replacement therapy after thyroid surgery. B-ENT 2006; 2: 129-133

[12] Dombrowski S, Kostev K. Use of electronic medical records in the epidemiological research. Cuvillier Verlag; 2017

[13] Mistry D, Atkin S, Atkinson $\mathrm{H}$ et al. Predicting thyroxine requirements following total thyroidectomy. Clin Endocrinol (Oxf.) 2011; 74: 384-387
[14] Ojomo KA, Schneider DF, Reiher AE et al. Using body mass index to predict optimal thyroid dosing after thyroidectomy. J Am Coll Surg 2013; 216: 454-460

[15] Di Donna V, Santoro MG, de Waure C et al A new strategy to estimate levothyroxine requirement after total thyroidectomy for benign thyroid disease. Thyroid Off. J Am Thyroid Assoc 2014; 24: 1759-1764

[16] Scargill J], Livingston M, Holland D et al. Monitoring thyroid function in patients on levothyroxine. Assessment of Conformity to National Guidance and Variability in Practice. Exp Clin Endocrinol Diabetes 2017; 125: 625-633 